\title{
Os congressos brasileiros de geografia entre 1909 e $1944^{*}$
}

\section{Brazilian geography congresses from 1909 to 1944}

Luciene Pereira Carris Cardoso

Doutora em História pela Universidade do Estado do Rio de Janeiro. Rua Pacheco Leão, 704/5A

22460-030 - Rio de Janeiro - RJ - Brasil lucienecarris@hotmail.com

Recebido para publicação em julho de 2009. Aprovado para publicação em janeiro de 2011.

CARDOSO, Luciene Pereira Carris. Os congressos brasileiros de geografia entre 1909 e 1944. História, Ciências, Saúde Manguinhos, Rio de Janeiro, v.18, n.1, jan.-mar. 2011, p.85-103.

\section{Resumo}

Analisa a promoção dos congressos brasileiros de geografia pela Sociedade de Geografia do Rio de Janeiro entre 1909 e 1944, identificando algumas permanências e rupturas. A análise desses encontros científicos revela não apenas a preocupação com o estado da arte ou a evolução da disciplina. Eles constituem um bom termômetro para se avaliar as transformações que se operavam no país, nos âmbitos social, econômico e político.

Palavras-chave: congressos de geografia; território; Brasil.

\section{Abstract}

This analysis of the Brazilian geography congresses sponsored by the Geography Society of Rio de Janeiro between 1909 and 1944 identifies commonalities as well as differences over the years. Given how these scientific events focused on both the state of the art within the field as well as on its overall development, such an analysis serves as a good thermometer for measuring the social, economic, and political changes underway in Brazil.

Keywords: geography congresses; territory; Brazil. 
$\mathrm{C}$ riada em fins dos Oitocentos por iniciativa do senador Manuel Francisco Correia, em 25 de fevereiro de 1883, a Sociedade de Geografia do Rio de Janeiro (SGRJ) tomava como modelo as congêneres europeias. Inspiradas no movimento europeu, as sociedades geográficas proliferaram no Novo Mundo. Essas entidades pretendiam divulgar o conhecimento científico por meio de intercâmbio de publicações, da participação em congressos e da troca de correspondência com congêneres estrangeiras, principalmente europeias (López-Ocón, 1996). ${ }^{1}$ Porém seus objetivos se direcionavam para a organização dos espaços nacionais. Assim, de forma semelhante às congêneres europeias, também se tornavam instrumentos específicos a serviço do Estado, pois as informações levantadas auxiliavam no reconhecimento do território, o que certamente contribuía para a formação de um imaginário nacional. A entidade, desde sua criação, envolveu-se em vários projetos que visavam descortinar o espaço nacional aos brasileiros, tornando-se um espaço de sociabilidade intelectual e de divulgação científica.

Entre os anos de 1909 e 1940 foram promovidos pela SGRJ dez certames geográficos. Para efeito de comparação analítica, optamos por agrupar esses congressos em dois intervalos de tempo. O primeiro a ser considerado se estende entre os anos de 1910 e 1926. Esses encontros tiveram lugar em diversas capitais brasileiras, contaram com financiamento de órgãos públicos e com participação de entidades estaduais, que os acolhiam, levando ao aparecimento de grande número de contribuições que privilegiavam temáticas locais. O segundo momento compreende os eventos que se realizaram nos anos de 1940 e 1944, cuja organização passou a receber o patrocínio do governo de Getúlio Vargas e a contar com a colaboração do Instituto Brasileiro de Geografia e Estatística (IBGE) e do Conselho Nacional de Geografia (CNG).

Tabela 1

Congressos brasileiros de geografia (1909-1944)

\begin{tabular}{|c|c|c|c|}
\hline Data e local de realização & Total de adesões & Total de trabalhos & Publicação \\
\hline 1ㅇ Rio de Janeiro (1909) & 557 & 108 & 12 volumes (1494 páginas) \\
\hline 2o São Paulo (1910) & 348 & 79 & - \\
\hline 3을itiba (1911) & 366 & 79 & - \\
\hline 4을 Recife (1915) & 213 & 48 & 3 volumes (543 páginas) \\
\hline 5o Salvador (1916) & 1.057 & 111 & 2 volumes (1877 páginas) \\
\hline 6o Belo Horizonte (1919) & 464 & 69 & - \\
\hline 7ㅇ João Pessoa (1922) & 94 & 69 & - \\
\hline 8 Vitória (1926) & 225 & 55 & 1 volume (376 páginas) \\
\hline 9 Florianópolis (1940) & 2.137 & 215 & 5 volumes (3934 páginas) \\
\hline 10으o de Janeiro (1944) & 2.496 & 167 & 2 volumes (1226 páginas) \\
\hline
\end{tabular}

Nota:Tabela elaborada a partir das informações constantes dos anais dos congressos brasileiros de geografia $\left(1^{\circ}\right.$, $44^{\circ}, 5^{\circ}$, $8^{\circ}$, 9으 e $10^{\circ}$ ).

Na Tabela 1, em relação ao primeiro intervalo indicado, verifica-se que o $1^{\circ}$ e o $5^{\circ}$ congressos, que tiveram lugar, respectivamente, no Rio de Janeiro e em Salvador, alcançaram maior índice de adesões, seguidos em ordem decrescente dos de Belo Horizonte (1919), Curitiba (1911), São Paulo (1910), Vitória (1926), Recife (1915) e João Pessoa (1922). A 
mesma situação se apresenta no que se refere ao número de contribuições publicadas, sendo que a memória dos eventos de São Paulo, Curitiba, Belo Horizonte e João Pessoa não foi registrada sob a forma de anais. E, diga-se de passagem, a jornada na pauliceia de 1910, como reconheceria mais tarde o sócio Lindolfo Xavier (1917, p.6), "não teve o brilho que se desejava por motivos independentes da vontade dos diretores da Sociedade de Geografia".

A ideia de realizar um congresso brasileiro de geografia partira do sócio José Arthur Boiteux em 1908, que sugeriu que a Sociedade de Geografia promovesse uma reunião geográfica a fim de comemorar os 87 anos da independência nacional. O projeto foi encampado pela instituição recebendo apoio de diversos estados. Na programação previase a realização de excursões às casas em que viveu o Patriarca da Independência, José Bonifácio de Andrada e Silva, na ilha de Paquetá, e em Niterói, onde faleceu. Além disso, paralelamente ao encontro pretendia-se a realização de uma exposição cartográfica. Todavia, esta somente pôde ocorrer após o evento, entre os dias 22 e 30 de setembro, com a mostra de 231 mapas, plantas e cartas geográficas dos estados, e não logrou o sucesso desejado.

Poucos governos estaduais mandaram seus mapas, com exceção de Santa Catarina, Minas Gerais e São Paulo, este último representado pela Comissão Geográfica e Geológica, que enviou uma coleção de relatórios e folhas topográficas. Alguns justificaram a ausência, como percebemos na correspondência remetida à Sociedade por Jerônimo de Souza Monteiro, presidente do Espírito Santo e por Antônio Francisco de Gouveia, primeiro vice-presidente do Instituto Arqueológico e Geográfico Alagoano. Este último afirmava possuir pouquíssimos exemplares e que não os remeteria, devido à possibilidade de extravio. Seja como for, fizeramse representar no $1^{\circ}$ Congresso, ao todo, 14 estados, totalizando 68 entidades brasileiras, com maior presença do Sudeste e Sul do país e destaque para Rio de Janeiro, São Paulo, Rio Grande do Sul e Minas Gerais. As atividades do 1ํㅡㄹ Congresso Brasileiro de Geografia iniciaramse no Palácio Monroe, com a presença do presidente da República, Nilo Peçanha, e outras autoridades, num total de 140 personalidades.

As contribuições apresentadas ao 1ํㅡㄹ Congresso demonstram que alguns temas se sobressaíam: a questão da revisão da nomenclatura dos acidentes geográficos, a reforma do ensino e o problema da elaboração dos mapas cartográficos. Salientava-se a necessidade de mais informações sobre o hinterland brasileiro, ao passo que se reafirmava o caráter utilitário e pragmático dos estudos geográficos, dentro da ideia da utilização da ciência para o progresso e para a integração nacional. ${ }^{2}$ Ao que tudo indica, o certame obteve grande repercussão, tanto que se planejou a realização periódica de outros, como o convocado para o ano de 1910 na cidade de São Paulo que, ao que tudo indica, não obteve o mesmo sucesso do encontro anterior.

É possível atribuir o fracasso, em parte, à complexidade da preparação de empreendimentos acadêmicos de tal porte fora da capital da República, embora a direção da SGRJ se empenhasse em levá-los a cabo. Acrescente-se a isso as longas distâncias a serem vencidas pelo público-alvo e a precariedade das comunicações na época. Uma pista dessas dificuldades pode ser percebida no relatório do $4^{\circ}$ Congresso de Geografia, promovido em 1915, no Recife. A escassez de verbas, a precariedade das comunicações com a Sociedade do Rio de Janeiro, o clima de incerteza provocado pelo início da Primeira Guerra Mundial 
foram alguns dos contratempos que, agravados por disputas políticas locais, levaram o general Dantas Barreto - então governador de Pernambuco - a chamar para si a responsabilidade de organizar a reunião científica, cujas sessões se realizaram no Ginásio Pernambucano (Congresso..., 1915, p.61).

O certo é que Dantas Barreto se valeu do prestígio do cargo que ocupava e conseguiu convocar 209 participantes, oriundos majoritariamente de Pernambuco e estados vizinhos, aos quais se somaram os delegados da associação do Rio de Janeiro (Congresso..., 1915, p.22-25). Mas a predominância de congressistas nordestinos interferiu na consecução do programa, distribuído por 12 comissões científicas, consoante as especialidades da disciplina. ${ }^{3}$ A pauta dos trabalhos concentrou-se, sobretudo, na problemática das secas que afetavam o Nordeste do país e em assuntos que vinham sendo abordados desde o primeiro encontro patrocinado pela Sociedade em 1909, a exemplo da revisão da nomenclatura das cidades e acidentes geográficos, a adoção do esperanto como língua universal e a reforma do ensino da geografia nas escolas (Congresso..., 1915, p.54), bem como a necessidade da erradicação do analfabetismo no país. Nesse sentido, o general Dantas Barreto expunha um raciocínio cartesiano: "na propaganda dos conhecimentos geográficos, não esqueçamos que é preciso, como condição preliminar, que o povo saiba ler" (Congresso..., 1915, p.53).

Por outro lado, causa surpresa a ausência de debates sobre um dos temas que, naquela altura, mais suscitava polêmica entre os estudiosos da geografia: a fixação dos limites interestaduais. Pesquisando as atas das reuniões preparatórias do congresso, contudo, descobre-se que o silêncio fora provocado pelo próprio general Dantas Barreto, que proibira tal discussão com a justificativa de que "a atual divisão político-administrativa do Brasil é fruto de circunstâncias históricas de sua formação e nem mesmo por via de uma revisão constitucional poderá ser alterada sem gravíssimas consequências que devemos evitar a todo o transe, escudados no mesmo amor pátrio e no mesmo anelo do Brasil gigante" (Pereira, 1915, p.37-38).

Em 1916, na cidade de Salvador, sob a presidência de Teodoro Sampaio, aconteceu o 5o Congresso Brasileiro de Geografia, mais tarde considerado um dos mais importantes do período que se estende de 1909 a 1926 (Souza, 1941, p.16). Reuniu um total de 1.057 participantes. Paralelamente ao congresso, que pretendia traçar um grande painel da geografia pátria consoante o ideário nacionalista então difundido, promoveu-se uma exposição de 104 documentos, entre cartas, mapas e fotografias, e inaugurou-se uma galeria com os 19 vultos nacionais e estrangeiros que mais contribuíram para o desenvolvimento da disciplina no Brasil. À guisa de informação, cabe mencionar que a coleção era composta dos seguintes nomes: Peter Lund, Louis Agassiz, Frederic Hartt, Orville Derby, almirante Ernest Mouchez, Henri Coudreau, Élisée Réclus, von Martius, Teodoro Sampaio, Euclides da Cunha, Cândido Rondon, Couto de Magalhães, João Barbosa Rodrigues, Cândido Mendes de Almeida, João Severiano da Fonseca, Antônio Rebouças, Alfredo Moreira Pinto e barão Homem de Mello (Congresso..., 1916a, p. 12-13).

Os anais do 5 Congresso compreendem dois volumes. O primeiro contém o relatório de atividades, o regulamento e regimento do congresso, a relação de memórias apresentadas, além das resoluções e das moções. O segundo concentra os trabalhos das comissões científicas, tais como atas, pareceres, monografias. Mais uma vez, os trabalhos do certame se distribuíram 
por 12 seções cientificas. ${ }^{4}$ Todavia, em relação aos congressos anteriores, efetuaram-se algumas mudanças. Além de separar a seção de geografia física da de geografia política, incorporouse ao programa a de antropogeografia ou geografia humana; a seção de geografia biológica tomou a denominação de biogeografia, enquanto que a chamada geografia militante tratava das explorações geográficas (Congresso..., 1916a, p. 17). Criou-se também uma seção de monografias dedicadas a temáticas regionais que, por sinal, iria concentrar a maior parte dos trabalhos expostos - o que não é de estranhar, uma vez que $75 \%$ dos congressistas inscritos eram naturais do estado da Bahia.

Outra novidade a ser assinalada foi a introdução, no programa, de um segmento dedicado à geografia médica, área que buscava articular a climatologia com a medicina. Cientistas reconhecidos, Antônio do Prado Valladares (1916, p.433), professor da Faculdade de Medicina da Bahia, Otávio Torres (1916, p.443) e Alfredo Augusto da Matta (1916, p.513) discutiram a relação entre clima e doença, além de propostas para a organização de uma carta nosográfica das regiões do território brasileiro e do incentivo ao estabelecimento de associações destinadas ao estudo das doenças tropicais.

Entre os estudos antropogeográficos, vale a pena assinalar as monografias assinadas por Egas Moniz Barreto de Aragão e por Manuel Raimundo Querino. O primeiro apontava o uso equivocado do conceito de raça latina, para se referir aos povos cujos idiomas derivam do latim, noção que se disseminara com a Primeira Grande Guerra. Assegurava que o Brasil não possuía um tipo étnico definido. Sendo assim, "em vez de julgar lamentável a sua etnogênese, o povo brasileiro, deve, pelo contrário, orgulhar-se de ser uma officina gentiumm e de sentir correr-lhe nas veias o sangue de todas as raças das terras, encerrando assim na sua alma a própria alma da humanidade" (Aragão, 1916, p.554).

Já Manuel Querino, considerado hoje o primeiro estudioso afro-descendente a destacar a participação do negro na cultura brasileira, apresentou um alentado ensaio sobre costumes, hábitos e práticas introduzidas pelos escravos, enriquecido de material iconográfico de várias tribos africanas (Nunes, 2007). Na opinião de Querino (1916, p.628), "o africano foi um grande elemento ou o maior fator da prosperidade econômica do país: era o braço e nada se perdia do que ele pudesse produzir. O seu trabalho incessante, não raro, sob o rigor dos açoites, tornou-se a fonte da fortuna pública e particular".

Como era de se esperar, o contexto da guerra estimulou reflexões a respeito da utilidade estratégica do conhecimento geográfico, em consonância com o fenômeno de reafirmação dos sentimentos cívicos e do interesse pelas questões nacionais, identificado pelo historiador francês Maurice Agulhon (1996, p.12) como "patriotismo à moda de 1914". Assim, recomendava-se que o estudo da geografia fosse orientado pelo ideal cívico e seu ensino, incentivado nos "cursos civis e militares", de maneira que cada soldado ou marinheiro "se torne um perfeito conhecedor da geografia física do Brasil e dos países limítrofes" (Querino, 1916, p.726). O congressista Luiz José da Costa Filho (1916, p.722) afiançava que os exércitos beligerantes conheciam "não só de cor e salteado a geografia da Europa, mas, por igual, a geografia das outras partes do globo terrestre". Corroborando essa premissa, Luiz Lobo advertia que cabia à geografia militar devassar estrategicamente o território brasileiro, tão extenso e tão desconhecido, com a mesma tática empregada no território dos inimigos (Lobo, 1916). 
Diversas moções foram aprovadas no 5 Congresso, sobressaindo-se a que indicou a necessidade de elaborar as cartas geográficas do país na escala de um para milhão, de acordo com as convenções estipuladas nos congressos internacionais de Paris (1911) e Londres (1913). Registrou-se ainda um voto de louvor ao Clube de Engenharia pela edição de uma espécie de manual para o preparo de mapas, elaborado pelo engenheiro André Gustavo Paulo de Frontin (1916, p.151). Sugeriu-se, finalmente, a publicação de um "Dicionário geográfico dos estados", por ocasião das comemorações do centenário da independência.

Na documentação disponível não consta a edição dos anais do $6^{\circ}$ e do 7o congressos de geografia, realizados, respectivamente, nas cidades de Belo Horizonte (1919) e João Pessoa (1922). Há, no entanto, algumas pistas do primeiro, deixadas pelo secretário do Instituto Arqueológico, Histórico e Geográfico Pernambucano, Mário Melo. Os trabalhos dessa jornada foram divididos em seções científicas que englobavam as subdivisões da disciplina, mas incluíam também novos temas de interesse nacional, como os limites interestaduais e as comemorações do centenário, em 1922..$^{5}$ Paralelamente elaborou-se uma exposição de livros, mapas e outros objetos, separados por estados. Diferentemente dos anteriores, o evento de 1919 levantou o véu que encobria diversos litígios envolvendo a definição de limites entre alguns estados da federação (Melo, 1919, p.388).

De acordo com os apontamentos de Mário Melo (1919, p.388), com o objetivo de preparar o programa da jornada de Belo Horizonte a SGRJ promoveu, no Rio de Janeiro, um encontro preliminar, com representantes dos estados de Pernambuco, Alagoas, Paraíba, Bahia e Ceará. Nessa ocasião, tratou-se extra-oficialmente daquela problemática, buscando dirimir antigas disputas e firmar acordos demarcatórios baseados nos acidentes geográficos. Tudo leva a crer que a reunião articulava-se a um projeto mais amplo, de redefinição político-administrativa do território nacional, cujo encaminhamento vinha sendo discutido na Sociedade a partir de estudos ali apresentados por Ezequiel Augusto Ubatuba na década anterior. Nesse trabalho, o advogado Ubatuba (1922) concluía que as desproporções entre as áreas das unidades da Federação - herança das capitanias do período colonial constituíam um entrave para o desenvolvimento econômico do país. Para equacionar o problema, idealizou uma reforma político-administrativa que, entre outros pontos, dividia o território brasileiro de maneira mais equânime, em sua opinião, compreendendo 35 estados, além do Distrito Federal (p.21).

De qualquer forma, segundo Mário Melo (p.388), durante a reunião preparatória foram fixados acordos entre os representantes de Pernambuco e estados fronteiriços, exceto a Bahia. Os pernambucanos reivindicavam a integração de certas ilhas do rio São Francisco ao seu território, o que os baianos consideravam apropriação indevida. Diante do impasse, não se chegou a um acordo: "como ao congresso de geografia cabia apenas sancionar os acordos de limites chegados a bom termo pelos representantes dos estados, nada foi possível fazer" (p.395).

A demanda dos pernambucanos teria continuidade no 8o Congresso Brasileiro de Geografia, realizado em 1926, na cidade de Vitória, sob a presidência do general Cândido Mariano da Silva Rondon e a chancela do Instituto Histórico e Geográfico do Espírito Santo (Barreto et al., 1926, p.31). Esse evento ficou bastante fragmentado, uma vez que o governo do Espírito Santo aproveitou o ensejo para promover concomitantemente congressos de 
pedagogia e de esperanto, bem como uma exposição cartográfica e etnográfica, acrescida da mostra de produtos agrícolas intermunicipais.

Apesar da jornada compreender oito seções temáticas (Congresso..., 1926, p.31) ${ }^{6}$, a pauta de discussão convergiu para a demarcação das divisas entre os seguintes estados: Paraíba e Ceará; Pernambuco e Paraíba; Pernambuco e Ceará; Paraíba e Rio Grande do Norte. Novos confrontos se sucederam, e os delegados do Instituto Arqueológico e Geográfico Pernambucano, mais conhecido como Leão do Norte ${ }^{7}$, se recusaram a tratar das questões que afetavam o seu estado, sob alegação de que,

\begin{abstract}
os congressos de geografia não foram criados para tratar de limites. Ao contrário, havia cláusulas proibitivas de discussões sobre limites, porque o assunto concorria sempre para separar amigo e, na Bahia, houve um incidente pouco agradável entre sergipanos e baianos, só porque na descrição de um município baiano um congressista incluiu nos limites, como pertencente a boa terra, uma nesga dita contestada por Sergipe. Os congressos de geografia foram criados para animar o estudo de nossa pátria e aproximar periodicamente os que ao mesmo se dedicam (p.87).
\end{abstract}

Os participantes do encontro de Vitória pareciam partilhar da ideia de que o melhor caminho para fortalecer a federação e estreitar os laços interestaduais consistia em eliminar aqueles litígios, evitando a ameaça de uma 'guerra civil'. Porém, assinalavam alguns obstáculos que impediam a efetivação de acordos oficiais: a ausência de estudos topográficos, o espírito marcadamente regionalista da população, a oposição de vários políticos e a falta de continuidade administrativa nas gestões de prefeituras e de governos estaduais (Congresso, 1926, p.318). Cabe mencionar que as questões de limites interestaduais só seriam solucionadas em 1937, com a promulgação da Constituição do Estado Novo.

É possível observar algumas permanências, nas moções e sugestões aprovadas na plenária do 8 Congresso Brasileiro de Geografia. Como de costume postulava-se a erradicação do analfabetismo no país. Everardo Adolpho Backheuser, sócio atuante da SGRJ e personagem do cenário intelectual da época, foi uma das figuras destacadas no evento. Propôs o ensino da geografia em bases cientificas nas escolas e ressaltou a importância da elaboração de mapas topográficos e geológicos, do levantamento de informações estatísticas, da sistematização de dados meteorológicos, além da criação de uma cadeira de geopolítica nos currículos dos cursos superiores (Santos, 1989). As comissões científicas, por sua vez, manifestaram-se favoráveis à uniformização ou à correção de nomes de acidentes geográficos e de localidades, de acordo com a língua indígena ou com a tradição popular. Recomendava-se, também, a criação de uma cadeira para o ensino da língua tupi nas futuras faculdades de letras, bem como a implementação da disciplina estudos americanos, que englobaria o estudo da etnografia, da antropologia, da história, do folclore e das migrações indígenas.

\title{
Os congressos brasileiros de geografia no âmbito do sistema geográfico oficial
}

A complexidade das ações implementadas pelas políticas públicas direcionadas para integração do território nacional durante a era Vargas ensejou aquilo que denominamos cultura geográfica. Na esteira das reflexões de Ângela de Castro Gomes (2007), é possível inferir que, ao lado da sua dimensão temporal, própria de uma 'cultura histórica', uma 
sociedade também se empenha em definir o espaço físico que ocupa. Isso leva ao surgimento de uma 'cultura geográfica', capaz de estabelecer vínculos entre os indivíduos e o território pátrio. A categoria cultura geográfica aqui proposta articula-se, por um lado, com a cultura política do Estado Novo e por outro lado, aproxima-se do que poderia ser entendido como o campo da geografia dos anos 1930 e 1940. É viável supor que as políticas públicas desenvolvidas na era Vargas levaram a um conjunto de ações sistemáticas, originando uma cultura geográfica que visava responder a determinadas demandas. É evidente que, para desenvolver essa cultura geográfica, não se fez tábula rasa do passado. Procurou-se suporte nas experiências e estudos anteriores, empreendidos pela "prestigiosa Sociedade de Geografia do Rio de Janeiro que de longa data vem liderando no país as iniciativas e as realizações geográficas" (CNG, 1939). ${ }^{8}$ Estabeleceu-se, assim, uma espécie de via de mão dupla com os órgãos federais, que reconheciam a contribuição do tradicional reduto científico e recebiam, em troca, apoio e colaboração na implementação dos seus programas de trabalho. Não houve, portanto, conflito de interesses entre a associação e os organismos que seriam criados ao longo aos anos 1930, uma vez que o sistema geográfico oficial integrava antigos e modernos.

De acordo com a historiadora Ângela de Castro Gomes (2007, p.49), nos regimes autoritários a construção de uma cultura política ${ }^{9}$ vincula-se fortemente à implementação de políticas públicas, que investem de maneira eficiente e consciente na busca de sua legitimidade. No caso do Estado Novo, de acordo com a autora, o conjunto de medidas voltadas para a recuperação do "passado nacional brasileiro" revela uma dimensão específica de política pública em duplo sentido: no primeiro momento, buscou-se articular determinados setores do aparato de governo com atores sociais relevantes para a sociedade, a exemplo de artistas, cientistas e intelectuais; no segundo momento, delimitou-se o lugar de representação da nacionalidade por meio da leitura e da valorização deste mesmo passado, da formação de uma cultura histórica, no sentido tomado por Jacques Le Goff a Bernard Guenée, que caracteriza a relação de uma sociedade com o seu passado. Segundo Ângela, o conceito de cultura histórica permite "compreender melhor o quê especificamente os homens consideram o seu passado e que lugar lhe destinam em determinado momento" (p.46; grifo do original).

Em 1940, como foi mencionado, a Sociedade retomou a prática de promover reuniões periódicas da disciplina, interrompida em 1926. De acordo com as resoluções 42 e 48, respectivamente de 7 de julho e 30 de outubro de 1939, do CNG, "a Sociedade de Geografia do Rio de Janeiro e o Instituto Brasileiro de Geografia e Estatística, num entendimento cívico, deliberaram reiniciar a série dos Congressos Brasileiros de Geografia, realizando-os trienalmente" (CNG, 1939).

No contexto do que denominamos cultura geográfica do Estado Novo, a Sociedade promoveu duas jornadas científicas, em Florianópolis (1940) e no Distrito Federal (1944). Sintomaticamente, o 9o Congresso Brasileiro de Geografia seria precedido de intensa propaganda. O ministro Bernardino José de Sousa ${ }^{10}$, presidente da comissão organizadora, percorreu diversas capitais fazendo palestras e pronunciamentos, com objetivo de atrair especialistas e políticos para a reunião. Em suas andanças, Bernardino procurou destacar a 
importância dos estudos da geografia humana e a experiência da Sociedade, pioneira na promoção desses encontros:

Nosso pensamento foi apenas centralizar a investigação dos cultores da geografia nacional em torno de capítulos especiais do conhecimento geográfico do Brasil. Quem ler o capítulo das teses oficiais do congresso há de compreender que o nosso objetivo capital foi sobretudo pedir a atenção dos técnicos para os problemas da geografia humana do Brasil, e isto porque a nossa cultura geográfica não tem acompanhado como deveria o surto destes estudos no mundo civilizado. Isso coincide com a criação de cátedras de geografia humana nas Universidades do Rio de Janeiro e de São Paulo, onde têm pontificado mestres festejados como Deffontaines e Pierre Monbeig, a cujas lições devemos indubitavelmente uma brilhante plêiade de discípulos (Souza, 1941, p.19).

Com o objetivo de cuidar da organização do evento, cuja presidência de honra foi destinada a Getúlio Vargas, formaram-se dois comitês. O primeiro, de caráter normativo e centralizador, desenvolveria suas atividades no Distrito Federal. Compunha-se de sócios da SGRJ e de membros do IBGE, encarregados de determinar o programa, a estrutura e o funcionamento do 9o Congresso. O segundo reuniu-se em Florianópolis, local do evento, devendo tratar da sua execução física e responsabilizar-se pelo preparo da Exposição de Geografia e de Cartografia do Brasil. ${ }^{11}$

A opção pelo estado de Santa Catarina como sede do evento não foi aleatória. A escolha respondia a demandas bastante específicas, fruto da instabilidade política internacional, já que naquele estado se concentravam numerosos núcleos de imigrantes europeus, com predominância expressiva de indivíduos de origem alemã, alvos da propaganda nazista no exterior. Além disso, pretendia-se também homenagear o idealizador desses encontros, o citado José Arthur Boiteux, em sua terra natal.

A sessão solene de inauguração do 9ํㅡㄹ Congresso ocorreu na Assembleia Legislativa, em 7 de setembro de 1940. O interventor federal Nereu Ramos proferiu a palestra de abertura (Ramos, 1941, p.92), seguida dos pronunciamentos de Ivo de Aquino Fonseca, secretário de Estado do Interior, da Justiça e da Saúde (Aquino, 1941, p.92), e do ministro José Severiano da Fonseca Hermes. Este justificou sua indicação para representar a comissão organizadora, em substituição a José Carlos de Macedo Soares, presidente do IBGE, que se encontrava envolvido com o projeto do recenseamento a ser realizado naquele ano pelo órgão.

Tal como Bernardino de Sousa anunciara, a grande novidade que marcou o programa de 1940 e foi repetida em 1944 consistia na formulação de teses oficiais para dissertação. Ou seja, os organizadores preparavam previamente as proposições dos congressistas, distribuídas por seções que contemplavam áreas do conhecimento geográfico.

As monografias inscritas deveriam passar pelo crivo de comissões científicas, incumbidas de emitir parecer quanto ao mérito do seu conteúdo e a adequação à pauta indicada, de acordo com o modelo adotado nos congressos internacionais (Souza, 1941, p.19). Entretanto, ao lado dessas diretrizes de natureza acadêmica, as contribuições, por certo, sofriam outro tipo de apreciação, pois é sabido que a censura do Estado Novo se mostrava implacável quando se tratava de avaliar iniciativas de natureza cultural, que só poderiam ter lugar debaixo da tutela da ordem política. ${ }^{12}$ 
As jornadas de 1940 e 1944 reuniram figuras representativas do cenário intelectual brasileiro. Ao lado de conhecidas personalidades do panorama político-cultural do Estado Novo, figuravam funcionários do recém-criado IBGE, além de professores e dos primeiros egressos dos cursos das faculdades de filosofia, a exemplo de Alberto Ribeiro Lamego, José Setzer Gutman, Luiz de Castro Faria, Alvino Bertoldo Braune, Francisco Iglesias, Gregório Bondar, Odilon Nogueira Matos, Gilberto Freyre, Alice Piffer Canabrava, Carlos Delgado de Carvalho, Orlando Valverde, Jorge Zarur, Valter Spalding, Renato Teixeira Mendes, Osni Medeiros Régis, Pierre Monbeig, entre outros. Além disso, houve instituições que se fizeram representar por meio de trabalhos de caráter oficial, como o Ministério das Relações Exteriores, o Serviço de Proteção aos Índios, o Clube de Engenharia e a Faculdade de Filosofia, Letras e Ciências Humanas da Universidade de São Paulo.

De modo geral, como era de se prever, as teses oficiais confluíam para o desenvolvimento da cultura geográfica do Estado Novo, tanto na escolha dos temas para estudo quanto na busca de subsídios para orientar a formulação de políticas públicas. A esse respeito, no programa do congresso de 1940 a seção de geografia humana apresentava o item "Estudo funcional de um centro urbano", e solicitava-se aos autores de monografias que identificassem as condições geográficas e topográficas que influíam na formação de uma cidade, bem como o seu "histórico geograficamente interpretado". Na mesma seção, outro exemplo expressivo é a redação de um "inquérito antropogeográfico sobre um tipo de imigrante", em que se estimulava a redação de monografias que abordassem, entre outros aspectos, "a origem, a categoria social, a atitude do imigrante em relação ao trabalho, aos 'conceitos médios' sobre propriedade, família, religião, educação e as questões internacionais, e se o tipo era assimilável ou não" (Congresso..., 1941, p.31).

Os anais do 9o Congresso Brasileiro de Geografia compreendem cinco alentados volumes, contabilizando um total de 3.934 páginas (Congresso..., 1941). ${ }^{13}$ O primeiro volume reportase à parte preparatória: regulamento, resoluções, instruções para comunicações, lista de adesões, teses oficialmente recomendadas, atas das sessões e programa. Os demais concentram os 227 trabalhos aprovados para publicação e os respectivos pareceres das comissões técnicas. A Tabela 2 apresenta o número de teses apresentadas por comitê.

Tabela 2

$9^{\circ}$ Congresso Brasileiro de Geografia: teses e memórias apresentadas

\begin{tabular}{lc}
\multicolumn{1}{c}{ Comissões técnicas } & Total de teses e memórias \\
\hline Geografia matemática - cartografia & 19 \\
Geografia física & 33 \\
Biogeografia (geografia botânica e zoológica) & 11 \\
Geografia humana & 44 \\
Geografia econômica & 44 \\
Explorações geográficas e geografia histórica & 20 \\
Metodologia geográfica: regras e nomenclatura & 16 \\
Monografias regionais, estudos especiais da corografia & 40 \\
catarinense e da cidade de Florianópolis & \\
\hline
\end{tabular}

Fonte: Regulamento..., 1940, p.71. 
Como se pode constatar, a maior incidência de trabalhos recaiu sobre as seções de geografia humana e de geografia econômica, seguindo-se contribuições voltadas para a temática regional e monografias dedicadas ao estudo da geografia física. Afora a indicação recorrente da necessidade de elaborar uma carta topográfica brasileira, assunto que vinha sendo discutido desde 1909, as demais moções aprovadas pelas comissões técnicas espelham o contexto político e cultural que o país atravessava. Foram aprovados indicativos recomendando a criação de um curso de corografia brasileira no Instituto Nacional de Cinema Educativo; o preparo de um dicionário geográfico brasileiro, pelo CNG; a organização de roteiros e de planos de excursões de caráter científico-geográfico aos estados brasileiros, para serem publicados na Revista Brasileira de Geografia; a introdução das seções de geografia das calamidades e de geografia urbana nos próximos congressos; o estabelecimento de órgãos geográficos de âmbito estadual, tal como os que já existiam em Minas Gerais e em São Paulo. Finalmente, advertia-se aos congressistas que se dedicassem exclusivamente aos estudos de aspectos geográficos, deixando de lado as questões de natureza política. Deliberou-se ainda que os congressos brasileiros de geografia passariam a ter periodicidade trienal, devendo o próximo realizar-se em 1943, dessa feita no extremo norte do país, em Belém do Pará.

Contudo, nem todas as decisões foram unânimes. Há registro de discussões acaloradas, tal como a que se seguiu à proposta do professor Jorge Zarur, integrante da comissão de metodologia geográfica, regras e nomenclatura. Ele postulou a separação dos cursos de geografia e história nas faculdades de filosofia, e a criação de uma disciplina específica para tratar da metodologia do ensino da geografia. A moção teve acolhida favorável do plenário, porém o professor Pierre Monbeig, presidente da comissão de geografia humana, recomendou que não se deliberasse precipitadamente sobre o assunto. Colocada em votação pelo presidente da comissão organizadora, o ministro Bernardino de Sousa, e apesar das manifestações de protesto de muitos congressistas, a sugestão foi orientada para reexame, a pretexto de "atender ao apelo do sr. Prof. Pierre Monbeig, em homenagem à sua cultura e à colaboração que traz para os nossos trabalhos (Congresso... 1941, p.132).

Além da programação científica, foram planejadas atividades que buscavam reforçar a política cultural de cariz nacionalista, desenvolvida no Estado Novo: visitas ao Instituto Histórico e Geográfico de Santa Catarina, à Academia Catarinense de Letras e a estabelecimentos de ensino; exibições públicas de filmes produzidos pelo Instituto Nacional de Cinema Educativo; apresentação de demonstrações de educação física no estádio de Santa Catarina; uma excursão cientifica ao Vale de Itajaí, liderada pelo professor Pierre Monbeig; e uma homenagem ao catarinense José Arthur Boiteux, responsável pela introdução dos congressos de geografia no Brasil.

A comissão organizadora também patrocinou um ciclo de conferências, ao que tudo indica nas dependências do Clube 12 de Agosto. A primeira, pronunciada por Osvaldo Cabral, constava de relato histórico da evolução do estado de Santa Catarina. A segunda teve por objetivo apresentar uma comunicação técnica, acompanhada de exibição cinematográfica, acerca dos levantamentos aerofotogramétricos desenvolvidos pelo Sindicato Condor. A terceira, do professor Delgado de Carvalho, ofereceu um quadro da evolução da 
geografia humana, detendo-se no exame da contribuição de geógrafos europeus e norteamericanos. O ciclo seria encerrado pelo tenente-coronel Temístocles Sousa Brasil, com a palestra "Uma página da geografia", dedicada a estudantes do ensino primário, seguida da apresentação de "filmes geográficos" (Congresso..., 1949, v.1, p.134).

Conforme a periodização instituída nas resoluções 42 e 48 do CNG, o $10^{\circ}$ Congresso Brasileiro deveria se realizar em 1943, na capital do estado do Pará. Todavia, devido à entrada do Brasil na Segunda Guerra Mundial o evento seria adiado e transferido para o Rio de Janeiro. Convocado para se realizar em 1944, além dos órgãos do sistema geográfico oficial, recebeu as adesões do Ministério da Educação e Saúde e da Prefeitura do Distrito Federal.

Em relação ao encontro de Florianópolis, do ponto de vista de estrutura e funcionamento, o $10^{\circ}$ Congresso apresentou como novidade a introdução da seção de geografia das calamidades e a volta da geografia médica (Congresso..., 1949, v.1, p.34-35). A comissão organizadora central delimitava os assuntos relevantes para estudo. Por exemplo, na área de geografia médica, preocupavam-se com a distribuição geográfica da malária; em relação à geografia das calamidades, recomendava-se que os trabalhos se debruçassem sobre as pragas de gafanhotos e as enchentes dos rios em centros urbanos. As instruções para apresentação de trabalhos seguiam o mesmo modelo da jornada de 1940, ou seja, o programa fora previamente determinado com a formulação de 18 teses oficiais para dissertação, distribuídas pelas dez seções em que se dividiam as atividades. Manteve-se, também, a prática da avaliação prévia do mérito das comunicações, por comissões científicas.

Como era de prever, Getúlio Vargas ocuparia a presidência de honra do encontro, secundado por autoridades do Estado Novo, a exemplo de Gustavo Capanema, e por sócios beneméritos da SGRJ, tais como Cândido Rondon, Bernardino José de Sousa, João Severiano da Fonseca Hermes, Fernando Antônio Raja Gabaglia, Brás Dias de Aguiar, Édison Junqueira Passos e Emílio Fernandes de Sousa Doca. A comissão organizadora foi liderada pelo ex-chanceler José Carlos de Macedo Soares, presidente do IBGE e do IHGB. Em 11 de setembro de 1944 realizou-se a sessão plenária preparatória nas dependências do IHBG, no prédio do Silogeu Brasileiro (Raja Gabaglia, 1949a, p.112), ao passo que a cerimônia de instalação aconteceu no Palácio Tiradentes, com a presença do representante do presidente da República, o ministro Alexandre Marcondes Filho. Nessa solenidade, o professor Fernando Raja Gabaglia (1949b, p.122) - velho filiado da Sociedade - reafirmou a importância dos estudos da geografia política para o Estado Novo, "uma vez que os nexos entre as condições geográficas naturais e a estruturação política de um estado são inegáveis ... despida de quaisquer considerações subjetivistas, a noção de estado decorre do território, pois o estado é uma 'individualização geográfica'".

Compareceram à jornada 2.496 congressistas, inclusive estrangeiros, como os delegados da $2^{\mathrm{a}}$ Reunião Pan-americana de Consulta sobre a Geografia e Cartografia, e do doutor André C. Simonpietri, secretário da comissão de Cartografia do Instituto Pan-americano de Geografia e História, em viagem pelos países latino-americanos com os objetivos de levantar informações cartográficas e promover o intercâmbio de técnicos (Castro, 1949, p.170). Há que mencionar, ainda, a participação de representantes das embaixadas dos EUA, Portugal e França, do Conselho Nacional de Proteção aos Índios, da Faculdade Nacional de Filosofia, do Colégio Pedro II, do Clube de Engenharia, do IHGB, do Instituto de 
História e de Geografia Militar, do Conselho Nacional de Geografia, da Prefeitura do Distrito Federal, dos estados e dos territórios brasileiros.

Foram expostas 167 monografias no $10^{\circ}$ Congresso. Lamentavelmente, esse material não foi publicado na íntegra, limitando-se os anais a apenas dois volumes, o que nos impede de fazer um quadro, tal como realizado acerca do $9^{\circ}$ Congresso. De qualquer forma, no primeiro volume, impresso em 1949, encontram-se os textos relativos ao regulamento, ao programa de teses oficiais, às moções, às conferências, às excursões, bem como a edição de 37 teses resumidas e adaptadas. O segundo volume apareceu em 1952 e contém os trabalhos aprovados para a publicação das seguintes comissões: geografia histórica (15), geografia matemática (4), geografia física (5) e biogeografia (2).

A leitura desse material, embora contemple apenas quatro seções do evento, demonstra que os organizadores se esmeraram para reforçar a cultura geográfica do Estado Novo, de forma semelhante ao ocorreu no congresso de 1940. A questão imigratória, por exemplo, mereceu a atenção de diversos estudiosos, tal como o capitão Osmar Romão da Silva, cuja comunicação abordou a assimilação dos imigrantes entre os anos de 1934 e de 1944. A primeira data correspondia ao momento de profunda desassimilação decorrente da influência nazista. Para o militar, a situação só se alterou com a lei de nacionalização do ensino, promulgada em 1935, seguida da proibição de propaganda política estrangeira e utilização do idioma alemão em lugares públicos (Silva, 1949, p.173).

Também preocupado com controle dos imigrantes, o deputado e professor Xavier de Oliveira defendeu a ideia de uma redivisão administrativa do território brasileiro ${ }^{14}$ por meio da criação de 16 novas "unidades mediterrâneas", com características semelhantes às de colônia agrícola e militar. As unidades teriam sua população constituída por até $25 \%$ de europeus, ficando vedada a entrada de "elementos da raça amarela" (Oliveira, 1949, p.487). Oliveira sugeria a adoção de um sistema de cooperativa, que estabelecia o direito ao uso da terra após cinco anos, para o brasileiro nato e para o estrangeiro que se casasse com brasileira ou tivesse filhos nascidos no país. E recomendava, ainda, sucessivas partilhas do espaço nacional, "de tal jeito que consideremos a redivisão política periódica do território nacional um postulado a ser inscrito em nosso próprio estatuto fundamental. E deve ser feita baseada, em, apenas, três considerações: (1) a extensão territorial de cada estado; (2) a densidade demográfica de cada região; (3) o índice de progresso econômico e social a que houver atingido" (Oliveira, 1949, p.486).

Apesar das restrições impostas pela SGRJ, no que tange às moções e recomendações houve indicativos que despertaram boas polêmicas. A começar pelo velho problema dos limites interestaduais. O representante do Instituto Arqueológico, Histórico e Geográfico Pernambucano, o já mencionado Mário Melo, considerou o assunto inoportuno, uma vez que Carta Constitucional de 1937 havia extinguido quaisquer questões de limites (Congresso..., 1949, p.186). O embaixador Macedo Soares, porém, na qualidade de presidente da jornada científica, considerou válido o debate para a "retificação de pontos imprecisos ou duvidosos" (p.184). A posição do ex-diplomata encorajou outros participantes a tratarem daquela problemática, a exemplo de Azevedo Costa, Joaquim Ramalho e Benedito Quintino dos Santos (Congresso..., 1949, p.188-189). 
Por outro lado, certos congressistas voltaram suas atenções para delimitação do campo da disciplina, censurando comunicações que, no seu entender, não tratavam de temas de natureza geográfica, como fez Fábio de Macedo Soares Guimarães, secretário da comissão de geografia humana. Ele reconheceu a contribuição positiva de monografias de cunho econômico e social, voltadas para subsidiar a administração pública, porém advertiu: "francamente escapam à competência de um congresso de geografia" (Congresso..., 1949, p.203).

A provocação de Fábio foi respondida por Luis de Oliveira Belo, que manifestou a sua dificuldade em distinguir uma tese geográfica de teses de outras áreas do conhecimento, dúvida que acreditava compartilhar com a maior parte dos congressistas. Criou-se uma situação de mal-estar, uma vez que todos os trabalhos apresentados correspondiam às teses oficiais, preparadas pelos organizadores do evento, além de terem passado pela aprovação das comissões científicas (Congresso..., 1949, p.203). Outras intervenções também suscitaram animados debates. Na 3a sessão plenária, o ministro da Educação e Saúde, Gustavo Capanema, pronunciou uma conferência sobre o papel da geografia na formação da juventude brasileira. Em sua opinião, os cursos de geografia e história ministrados pelas faculdades de filosofia, de acordo com a legislação aprovada em 1939, destinavam-se ao preparo "primeiro do cientista em Geografia e História; segundo ... de professores para a escola secundária" (p.215). Para tanto, segundo o ministro, era necessário organizar laboratórios de estudos geográficos nos colégios e fomentar o intercâmbio de especialistas. Arrematando a fala, Capanema defendeu a implantação de uma nova reforma do ensino superior, com a separação dos cursos de geografia e de história, que passariam a ter práticas pedagógicas especificas. A proposta recebeu calorosos aplausos e o apoio unânime da plenária.

$\mathrm{Na}$ esteira das ideias de Capanema, o ministro João Severiano da Fonseca Hermes e o engenheiro Valdemar Lefèvre sugeriram a regulamentação da profissão de geógrafo e a criação de uma faculdade de geografia e cartografia (Congresso..., 1949, p.263-266). O indicativo foi aprovado com parecer emitido por Alírio de Matos, professor da Escola Politécnica, aconselhando o estabelecimento de escolas especializadas para a formação de topógrafos, agrimensores e engenheiros geodesistas, além de cursos de geografia nas faculdades de filosofia.

O debate tomou outro rumo quando Jorge Zarur, polemista conhecido, contrariando a opinião do ministro Capanema, argumentou que não estava na alçada das faculdades de filosofia diplomar cientistas, mas sim professores de ensino secundário. O professor Fernando Raja Gabaglia, por sua vez, advertiu que a moção aprovada pretendia apenas incentivar o estabelecimento de um curso técnico de geografia. Via com dificuldade a criação de uma escola superior voltada exclusivamente para o preparo de geógrafos, mas atentava para a necessidade de incorporar disciplinas pedagógicas nos currículos dos cursos de matemática, geografia e história. Não satisfeito com o encaminhamento da discussão, em outra oportunidade durante o Congresso, Jorge Zarur ${ }^{15}$ retomaria as propostas de Capanema, concluindo:

Nos últimos dez anos as universidades se têm esforçado em formar professores de geografia, geógrafos no verdadeiro sentido da palavra são poucos e quase todos autodidatas. Tenho esperança de que, no futuro, teremos também o técnico de geografia, o geógrafo 
profissional, como eu vi nas várias regiões americanas por onde passei, pesquisando e não somente ensinando geografia, mas indo ao campo para realizar pesquisas, construindo a ciência geografia e dando-nos um conhecimento maior do mundo em que vivemos (Zarur, 1949, p.386).

Além das comunicações, na programação científica houve seis conferências especiais. As três primeiras foram realizadas no auditório do Ministério da Educação. O professor Jorge Zarur inaugurou o ciclo, com a conferência "Geografia: ciência moderna a serviço do homem", seguido do comandante Braz Dias de Aguiar, com o relato dos trabalhos de levantamento dos rios da região amazônica, desenvolvidos pela Comissão Demarcadora de Limites. Por fim, falou o professor Everardo Backheuser, que sublinhou alguns dos aspectos singulares da geografia carioca.

Denominadas de "Tardes brasileiras", as conferências restantes tiveram lugar no IHGB e se caracterizaram pela valorização das grandezas naturais do território brasileiro, de acordo com o nacionalismo do Estado Novo. Deste modo, foram privilegiadas a "Região Nordestina", pelo professor Sylvio Fróes Abreu; a "Região Centro-Oeste", pelo coronel Lísias Augusto Rodrigues e a "Amazônia brasileira", pelo professor Artur César Ferreira Reis.

Além de abrir a discussão a respeito do ofício de geógrafo e da sua formação profissional, a plenária do $10^{\circ}$ Congresso Brasileiro de Geografia aprovou moções que sugeriam a permuta entre professores da disciplina de vários estados do Brasil, para o "efetivo conhecimento prático do território, finalidade considerada duplamente cultural e patriótica" (Congresso... 1949, p.475); a criação de gabinetes de geografia nas escolas secundárias; a introdução da seção de geografia urbana no programa dos próximos congressos, em consonância com os resultados das pesquisas efetuadas por técnicos do CNG sobre a revisão de nomenclaturas das cidades brasileiras. Esta moção, aliás, levaria a outra recomendação, aconselhando o estudo da disciplina por urbanistas e arquitetos dedicados aos planos de remodelação das cidades.

No encerramento dos trabalhos o $10^{\circ}$ Congresso conferiu o Prêmio José Boiteux, agraciando com medalhas de ouro, prata e bronze as comunicações aprovadas com louvor. Concedeu-se a medalha de ouro à monografia "O homem e a restinga", de autoria do professor Alberto Lamego Filho, estudo inspirado em Euclides da Cunha que tratou da colonização e da ocupação do estado do Rio de Janeiro. ${ }^{16}$ Foram laureadas com medalhas de prata as teses "A cartografia antiga e os fundamentos pré-históricos da nação brasileira", "O cearense na Amazônia: inquérito antropogeográfico sobre um tipo de imigrante" e "Lages, a rainha da serra", redigidas, respectivamente, pelo professor português Jaime Cortesão, pelo economista Samuel Benchimol e pelo engenheiro Vítor Peluso Junior. Receberam medalhas de bronze o ministro João Severiano da Fonseca Hermes, os professores Arthur César Ferreira Reis, Carlos Marie Cantão e Agnello Bittencourt, pelas respectivas contribuições, "O Rio de Janeiro: uma carta geral - aspectos físicos, expedições demarcadoras"; "Sertanistas, missionários e demarcadores: na revelação geográfica da Amazônia"; "Programa: tipo de excursões para fins didáticos"; e "Perfil do homem da Amazônia" (Congresso..., 1949, p.474).

Os congressos promovidos pela Sociedade de Geografia em 1940 e 1944 constituem um bom exemplo do funcionamento do sistema geográfico oficial instituído a partir de 1938. 
Evidenciam a predominância de um saber geográfico de caráter pragmático e utilitário, direcionado para o reconhecimento do espaço nacional e para subsidiar a ação do governo, consoante a cultura geográfica do Estado Novo. Por conseguinte, não é de estranhar sua "dimensão política" (Pereira, 2002, p.160). Porém isso não significa que sua contribuição ao conhecimento geográfico deva ser minimizada. É importante assinalar que, como atestam as discussões travadas, sobretudo na reunião de 1944, o campo da geografia no Brasil se encontrava em franca delimitação. Não por acaso pleiteava-se sua separação da história nos cursos das faculdades de filosofia. Além disso, despontava a preocupação em definir um perfil para o geógrafo profissional, cuja formação se presumia diferente daquela destinada aos docentes de ensino médio.

\section{NOTAS}

*Este artigo é parte da tese de doutorado Sociedade de Geografia do Rio de Janeiro: espelho das tradições progressistas (1910-1945), defendida no Programa de Pós-graduação em História Política da Universidade do Estado do Rio de Janeiro, sob a orientação da professora doutora Lúcia Maria Paschoal Guimarães. A pesquisa recebeu o apoio financeiro da Fundação de Amparo à Pesquisa do Rio de Janeiro (Faperj). Ver Cardoso, 2008; no prelo.

${ }^{1} \mathrm{O}$ autor compara as atividades de cinco sociedades geográficas da América Latina, entre 1833 e 1933, recuperando a história institucional de cada uma delas: Sociedade Mexicana de Geografia e Estatística, Instituto Geográfico Argentino, Sociedade de Geografia de Lima, Sociedade de Geografia de La Paz e Instituto Físico-Geográfico de Costa Rica.

${ }^{2}$ No âmbito acadêmico, os trabalhos do 1ํ Congresso Brasileiro de Geografia foram estruturados em 12 comissões. Para cada uma delas havia um comitê científico encarregado de avaliar o mérito das memórias, mapas e monografias, através de pareceres e de comentários técnicos, a saber: geografia matemática e cartografia; geografia física e política; vulcanologia e sismologia; hidrologia, potamografia e limnologia; oceanografia e correntes marítimas; meteorologia, climatologia e magnetismo; geografia biológica; geografia botânica e zoogeografia; antropologia e etnografia; ensino de geografia, regras e nomenclatura; geografia histórica; e explorações geográficas. A instauração de comitês científicos continuou a ser adotado nos eventos seguintes.

${ }^{3}$ Os trabalhos do $4^{\circ}$ Congresso dividiram-se em 12 comissões científicas: geografia física e política; geografia matemática e cartografia; vulcanologia e sismologia; hidrografia, potamografia e limnologia; oceanografia; meteorologia, climatologia e magnetismo terrestre; geografia biológica, geografia botânica e zoogeografia; antropologia e etnografia; geografia econômica e social; ensino de geografia; regras e nomenclatura; e geografia histórica.

${ }^{4} \mathrm{O}$ encontro foi organizado em 12 seções, a saber: geografia matemática (geoplanetologia, noções topográficas e geodésicas, cartografia); geografia física (aerologia, oceanografia, geomorfologia); vulcanologia e sismologia; climatologia e geografia médica; biogeografia (fitogeografia e zoogeografia); antropogeografia ou geografia humana; geografia política e social; geografia econômica e comercial; geografia agrícola; geografia militante e geografia histórica; ensino da geografia, regras e nomenclatura; e monografias descritivas regionais.

${ }^{5}$ Os trabalhos dessa jornada ramificaram-se em oito seções: geografia matemática; geografia física; biogeografia e etnografia; geografia política e geografia econômica, metodologia geográfica; monografias regionais; limites interestaduais; e comemorações do centenário de 1922.

${ }^{6}$ Nessa jornada, os trabalhos foram distribuídos da seguinte forma: geografia matemática (geoplanetologia e noções geodésicas e topográficas, cartografia); climatologia e geografia médica do Brasil; fitogeografia e zoogeografia; antropogeografia, etnologia e etnografia; geografia econômica, comercial, agrícola e industrial; geografia histórica, geografia política e social; geologia, paleogeografia e mineralogia; fisiografia, aeorologia, oceanografia, hidrografia terrestre, potamografia, limnologia, fisiografia das terras, orografia, vulcanologia, aerografia e nesografia.

${ }^{7}$ Sobre o Instituto Arqueológico, Histórico e Geográfico Pernambucano, ver Ferrão, 2001. 
${ }^{8}$ A resolução 22 de 18 de julho de 1938 da Assembleia Geral do CNG integrava as seguintes entidades no âmbito de um sistema geográfico: Sociedade de Geografia do Rio de Janeiro, Instituto Histórico e Geográfico Brasileiro, Academia Brasileira de Ciências, Clube de Engenharia e a Associação dos Geógrafos Brasileiros.

${ }^{9}$ A noção de cultura política aqui utilizada inspira-se na definição de Ângela de Castro Gomes (2007, p.49), em que cultura política é entendida como "um sistema de representações complexo e heterogêneo capaz de permitir a compreensão dos sentidos que um determinado grupo atribui a uma dada realidade social, em determinado momento e lugar".

${ }^{10}$ Bernardino José de Sousa, bacharel em direito pela Faculdade da Bahia, destacou-se como deputado estadual e como ministro do Tribunal de Contas da União; também atuou como professor de geografia e de história. Sobre a sua trajetória pessoal, ver Tapajós, 1996, p.161.

${ }^{11}$ A Exposição constava de obras brasileiras de geografia, de cartas geográficas do Brasil, e de seus estados e municípios, fotografias e aparelhos geográficos (Congresso..., 1941, p.27).

${ }^{12}$ A esse respeito, ver Capelato, 1998, p.100-103.

${ }^{13}$ Os cinco volumes de anais foram editados entre os anos de 1941 e 1944, pelo Serviço Gráfico do IBGE.

${ }^{14}$ Xavier de Oliveira, em 1946, propôs uma nova redivisão política do Brasil, com a criação de 45 estados e nenhum território, mantendo a capital no Rio de Janeiro (Oliveira, 1946).

${ }^{15} \mathrm{O}$ geógrafo Jorge Zarur especializou-se nos EUA, onde desenvolveu pesquisas de campo, o que certamente pesou nas suas argumentações. No Brasil, entre outras funções, ocupou o cargo de diretor da Divisão de Geografia do CNG. Sobre a trajetória de Jorge Zarur, ver Guerra, 1958, p.315.

${ }^{16}$ Vale acrescentar que no 9o Congresso a contribuição de Lamego, intitulada "O homem e o brejo", também foi aprovada com louvor. A obra de mesmo nome aborda a formação da planície campista, enquanto que "O homem e a restinga" descreve as regiões litorâneas. As duas obras foram publicadas pelo CNG e até hoje são referências para os estudiosos (Congresso..., 1949, p.475).

\section{REFERÊNCIAS}

AGULHON, Maurice.

Histoire vagabonde: la politique em France, d'hier à aujourd'hui. Paris: Gallimard. t.3. 1996.

AQUINO, Ivo de.

Discurso na sessão solene de instalação. In: Congresso Brasileiro de Geografia, 9., 1940, Florianopólis. Anais... Rio de Janeiro: Serviço Gráfico do IBGE. v.1., p.92-93. 1941.

ARAGÃO, Egas Moniz Barreto.

Um falso conceito de raça em

antropogeografia. In: Congresso Brasileiro de Geografia, 5., 1916, Salvador. Anais... Salvador: Imprensa Official do Estado. v.1. p.551-565.1916.

BARRETO, Carlos Xavier Paes et al. (Org.). Regulamento do 8 o Congresso Brasileiro de Geografia. In: Congresso Brasileiro de Geografia, 8., 1926, Vitória. Anais... S.l.: s.n. v.1. 1926.

CAPANEMA, Gustavo.

Discurso na $3^{\underline{a}}$ sessão plenária em 15 de setembro de 1944. In: Congresso Brasileiro de Geografia, 10., 1944, Rio de Janeiro. Anais... Rio de Janeiro: Conselho Nacional de Geografia. v.1. 1949.
CAPELATO, Maria Helena R.

Multidões em cena: a propaganda política no varguismo e no peronismo. Campinas: Papirus. 1998.

CARDOSO, Luciene P. Carris.

Sociedade de Geografia do Rio de Janeiro: espelho das tradições progressistas (1910-1945). Tese (Doutorado em História) - Instituto de Filosofia e Ciências Humanas, Universidade do Estado do Rio de Janeiro, Rio de Janeiro. 2008.

CARDOSO, Luciene P. Carris. Um lugar para geografia nacional: Sociedade de Geografia do Rio de Janeiro (1883-1945). São Paulo: Editora Annablume. no prelo.

CASTRO, Cristóvão Leite de. 2ª sessão plenária em 13 de setembro de 1944. In: Congresso Brasileiro de Geografia, 10., Rio de Janeiro. Anais... Rio de Janeiro: Conselho Nacional de Geografia. v.1. 1949.

CNG.

Conselho Nacional de Geografia. Resolução n.22 de 18 de julho de 1938. Revista Brasileira de Geografia, Rio de Janeiro, v.1, n.3, p.143. 1939. 
CONGRESSO..

Congresso Brasileiro de Geografia, 9., 1940, Florianópolis. Anais... Rio de Janeiro: Serviço Gráfico do IBGE. v.1. 1941.

CONGRESSO...

Congresso Brasileiro de Geografia, 8., 1926, Vitória. Anais... S.1.: s.n. v.1. 1926.

CONGRESSO...

Congresso Brasileiro de Geografia, 5., 1916a, Salvador. Anais... Salvador: Imprensa Official do Estado. v.1. 1916.

CONGRESSO...

Congresso Brasileiro de Geografia, 4., 1915, Recife. Anais... Recife: Imprensa Oficial. v.1. 1916b.

COSTA FILHO, Luis José da.

A geografia e a guerra. In: Congresso Brasileiro de Geografia, 5., 1916, Salvador. Anais...

Salvador: Imprensa Official do Estado. v.2. 1916.

FERRÃO, Luiz Felipe.

Instituto Arqueológico Geográfico Pernambucano: um tributo à memória regional (1848-1911).

Dissertação (Mestrado em História) - Instituto de Filosofia e Ciências Humanas, Universidade do Estado do Rio de Janeiro, Rio de Janeiro. 2001.

FRONTIN, André Gustavo Paulo de.

Clube de Engenharia: instruções para a construção de cartas geográficas. In: Congresso Brasileiro de Geografia, 5., 1916, Salvador. Anais... Salvador: Imprensa Official do Estado. v.1. 1916.

GOMES, Ângela de Castro.

Cultura política e cultura histórica no Estado Novo. In: Abreu, Martha; Soihet, Rachel; Gontijo, Rebeca (Org.). Cultura política e leituras do passado: historiografia e ensino de história. Rio de Janeiro: Civilização Brasileira. p.43-63. 2007.

GUERRA, Antônio Teixeira.

Vultos da geografia brasileira. Revista Brasileira de Geografia, Rio de Janeiro, v.20, n.3. 1958.

LOBO, Luiz.

A geografia militar no Brasil. In: Congresso Brasileiro de Geografia, 5., 1916, Salvador. Anais... Salvador: Imprensa Official do Estado. v.2. p.768-781. 1916.

LÓPEZ-OCÓN, Leoncio.

Les sociétés de géographie: un instrument de diffusion scientifique en Amérique Latine au début du XXe siécle. In: Petitjean, Patrick (Dir.). Les sciences hors d'Occident au XX $X^{e}$ siécle. Paris: Orstom. p.79-85. 1996.
MATTA, Alfredo Augusto da.

Noções de climatologia de Manaus. In:

Congresso Brasileiro de Geografia, 5., 1916, Salvador. Anais... Salvador: Imprensa Official do Estado. v.1. 1916.

MELO, Mário.

6o Congresso Brasileiro de Geografia. Revista do Instituto Arqueológico, Histórico e Geográfico de Pernambuco, Recife, v.21, n.103,104. 1919.

NUNES, Eliane.

Manuel Raimundo Querino: o primeiro historiador da arte baiana. Revista Ohun, Salvador, ano 3, n.3, p.237-261. 2007.

OLIVEIRA, Xavier de.

Relação das teses premiadas, mensagens, moções, indicações e comunicações. $2^{\mathrm{a}}$ sessão plenária em 13 de setembro de 1944. In: Congresso Brasileiro de Geografia, 10., 1944, Rio de Janeiro. Anais... Rio de Janeiro: Conselho Nacional de Geografia. v.1. 1949.

OLIVEIRA, Xavier de.

Redivisão política e territorial do Brasil: estados de fronteira, estados mediterrâneos e o Ministério de Terras, Migração e Colonização. Rio de Janeiro: Imprensa Nacional. 1946.

PEREIRA, J. Thimes.

O Brasil e a sua divisão territorial sob o ponto de vista político, social e econômico. In: Congresso Brasileiro de Geografia, 4., 1915, Recife. Anais... Recife: Imprensa Oficial. v.2. 1915.

PEREIRA, Sérgio Luiz Nunes.

Sociedade de Geografia do Rio de Janeiro: origens, obsessões e conflitos (1883-1944). Tese

(Doutorado em Geografia) - Faculdade de Filosofia, Letras e Ciências Humanas, Universidade de São Paulo, São Paulo. 2002.

QUERINO, Manuel Raimundo.

A raça africana e os seus costumes na Bahia. In: Congresso Brasileiro de Geografia, 5., 1916, Salvador. Anais... Salvador: Imprensa Official do Estado. v.2. 1916.

RAJA GABAGLIA, Fernando Antonio. Discurso na sessão plenária preparatória. In: Congresso Brasileiro de Geografia, 10., 1940, Florianopólis. Anais... Rio de Janeiro: Conselho Nacional de Geografia. v.1. 1949a.

RAJA GABAGLIA, Fernando Antonio. Discurso na sessão solene de instalação. In: Congresso Brasileiro de Geografia, 10., 1940, Florianopólis. Anais... Rio de Janeiro: Conselho Nacional de Geografia. v.1. 1949b.

RAMOS, Nereu.

Discurso na sessão solene de instalação.

Conferência. In: Congresso Brasileiro de 
Geografia, 9., 1940, Florianópolis. Anais..., Rio de Janeiro: Serviço Gráfico do IBGE. 1941.

REGULAMENTO...

Regulamento do 9 o Congresso. In: Congresso Brasileiro de Geografia, 9., 1940, Florianópolis. Anais... Rio de Janeiro: Serviço Gráfico do IBGE. v.1, p.71. 1941.

SANTOS, Sydney M. G. dos.

A cultura opulenta de Everardo Backheuser: os conceitos e as leis básicas de geopolítica. Rio de Janeiro: Carioca Engenharia. 1989.

SILVA, Osmar Romão da.

Assimilação em Santa Catarina. In: Congresso Brasileiro de Geografia, 10., 1940,

Florianopólis. Anais... Rio de Janeiro: Conselho Nacional de Geografia. v.1. 1949.

SOUZA, Bernardino José de.

Conferência. In: Congresso Brasileiro de Geografia, 9., 1940, Florianópolis. Anais..., Rio de Janeiro, Serviço Gráfico do IBGE. v.1. 1941.

TAPAJÓS, Vicente et al. (Org.).

Dicionário biobibliográfico de historiadores, geógrafos e antropólogos brasileiros. Rio de Janeiro: IHGB. v.3. 1996.
TORRES, Octavio.

Descrição da distribuição da leishmaniose na Bahia. In: Congresso Brasileiro de Geografia, 5., 1916, Salvador. Anais... Salvador: Imprensa Official do Estado. v.1. 1916.

UBATUBA, Ezequiel Augusto.

O Brasil futuro. Revista da Sociedade de Geografia do Rio de Janeiro, Rio de Janeiro, t. 25, 26, 27, 1912-1922. 1922.

VALLADARES, Antônio do Prado. Delimitação do conceito cientifico das expressões tropicais, patologia tropical. In: Congresso Brasileiro de Geografia, 5., 1916, Salvador. Anais... Salvador: Imprensa Official do Estado. v.1. 1916.

XAVIER, Lindolfo Octávio.

Revista geográfica. Revista da Sociedade de Geografia do Rio de Janeiro, Rio de Janeiro, t.15, p.4-12. 1917.

ZARUR, Jorge.

Geografia: ciência moderna a serviço do homem. In: Congresso Brasileiro de Geografia, 10., 1944, Rio de Janeiro. Anais... Rio de Janeiro: Conselho Nacional de Geografia. v.1. 1949. 